\title{
A Questão do Gênero nas Brincadeiras Infantis: um Estudo de Caso
}

\author{
The Issue of Gender in Children's Play: a Case Study
}

Ednélia Francisco dos Santos

Universidade Estadual de Maringá

neliafrancis@hotmail.com

Eliane Rose Maio Braga

Universidade Estadual de Maringá

elianerosemaio@yahoo.com.br

\section{Resumo}

Este texto tem por objetivo analisar de que forma as brincadeiras infantis podem estruturar os papéis socialmente definidos no que se refere à noção de gênero dentro do contexto escolar. Os pressupostos teórico-metodológicos utilizados neste trabalho recobrem a pesquisa de campo subsidiada pela Teoria Histórico-Cultural e pela Perspectiva PósEstruturalista. Entre os resultados obtidos, destaca-se o pensamento de alguns sujeitos da pesquisa, a saber, professoras e equipe pedagógica de uma Instituição de Educação Infantil, a respeito do gênero, ora como sinônimo de sexo, ora como classificação gramatical entre feminino e masculino. Por outro lado, destaca-se, também, o entendimento de gênero enquanto uma construção social. Quanto às brincadeiras, não houve consenso entre as entrevistadas.

Palavras - Chave: Gênero; Brincadeira Infantil; Formação de Professores; Teoria Histórico-Cultural; Perspectiva Pós-Estruturalista.

\begin{abstract}
This paper aims to examine how children's play can structure the socially defined roles in relation to the notion of gender within the school context. The theoretical and methodological assumptions used in this study cover the practice research funded by the Historic-Cultural Theory and Post-Structuralist Perspective. Among the results found, there is the thought of some research subjects, namely teachers and teaching staff of an Institution of Early Childhood Education, about gender, sometimes taken as a synonym for sex, or as a grammatical classification between female and male. On the other hand, there is also the understanding of gender as a social construction. As for plays, there was no consensus among the interviewees.
\end{abstract}

Keywords: Gender; Children's play; Teacher Training; Cultural Historical Theory; Post-structuralist Perspective. 


\section{Introdução}

O presente texto apresenta uma análise por meio da qual se pretende evidenciar de que forma as brincadeiras infantis em uma Instituição de Educação Infantil podem estruturar os papéis socialmente definidos na questão de gênero. Esta temática se constituiu como objeto de estudo para a realização do Trabalho de Conclusão de Curso (TCC), do curso de Pedagogia da UEM, no ano de 2010. Trata-se de uma pesquisa de campo, desenvolvida na Instituição de Educação Infantil Casa de Davi, em São Tomé (PR). Para atender nossos objetivos, utilizamos o método qualitativo de pesquisa e o instrumento de coleta de dados denominado 'entrevista semiestruturada'.

Para Chizzotti (2003), a pesquisa qualitativa readquire hoje um campo transdisciplinar evolvendo as Ciências Humanas e Sociais, assumindo tradições ou multiparadigmas de análise derivadas das diferentes teorias, nas quais se adotam vários métodos de investigação para o estudo de um fenômeno situado, 'procurando tanto encontrar o sentido desse fenômeno quanto interpretar os significados que as pessoas dão a eles' (CHIZZOTTI, 2003, p. 2).

Conforme Ludke e André (1986), alguns dos métodos de coleta de dados que a pesquisa qualitativa dispõe são: a observação, a entrevista e a análise documental. Para os autores, as entrevistas podem variar em não totalmente estruturada, que é uma entrevista em que não há a imposição de uma ordem rígida de questões, na qual, o/a entrevistado/a discorre sobre o tema proposto, com base nas informações, conhecimentos que ele/a detém sobre o tema proposto e que, no fundo, são a verdadeira razão da entrevista.

Há, também, a entrevista padronizada ou estruturada, na qual o/a entrevistador/a tem de seguir muito de perto um roteiro de perguntas feitas a todos/as os/as entrevistados/as de maneira idêntica e obedecendo à mesma ordem, tem-se, pois, neste caso, uma situação muito próxima da aplicação de um questionário, com a vantagem, no entanto, de se ter o/a entrevistador/a presente para algum eventual esclarecimento.

Outro tipo de entrevista é a semiestruturada, que se desenvolve a partir de um esquema básico, mas não aplicado rigidamente, permitindo que o/a entrevistador/a faça as adaptações necessárias (LUDKE; ANDRÉ, 1986).

Conforme Ludke e André (1986, p. 34-35):

o tipo mais adequado de entrevista, mais adequado para o trabalho de pesquisa que se faz atualmente em educação, aproxima-se mais dos esquemas mais livres, menos estruturados. As informações que se quer obter, e os informantes que se quer contatar, em geral professores, diretores, alunos e pais, são convenientemente abordáveis através de um instrumento mais flexível. [...] quando se quer conhecer, por exemplo, a visão de uma professora sobre o processo de alfabetização em uma escola de periferia ou a opinião de uma mãe sobre o problema de indisciplina ocorrido com seu filho, então é melhor nos prepararmos para uma entrevista mais longa, mais cuidada, feita provavelmente com base em um roteiro, mas com grande flexibilidade (LUDKE \& ANDRÉ, 1986, p. 34 - 35).

Com base nesses apontamentos, optamos pela pesquisa semiestruturada como método de coleta de dados para nossa investigação. A fim de conhecer as visões/ideias das professoras e da equipe pedagógica do Centro de Educação Infantil Casa de Davi, sobre a questão do gênero nas brincadeiras infantis, elaboramos um roteiro com perguntas a serem aplicadas aos sujeitos da pesquisa, contemplando os seguintes assuntos: idade; curso de formação; nível/turma dos/as alunos/as que trabalham; conceitos/ideias sobre gênero e brincadeira; encaminhamentos metodológicos para as atividades de brincadeiras; critérios de seleção para a compra dos brinquedos da instituição em questão; preferência dos/as alunos/as em relação às brincadeiras tidas como de menino e de menina; atitude das professoras frente a uma brincadeira de faz de conta em que o menino quisesse ser a mãe ou a menina ser o pai.

Paralelamente, realizamos estudos teóricos sobre formação docente, gênero, sexualidade, educação e brincadeira infantil, com intuito de sustentar nossas análises a partir dos dados coletados, já que na pesquisa qualitativa, os estudos teóricos dão a base para a análise da prática e, consequentemente, da qualidade do resultado.

Este texto está organizado em dois momentos: no primeiro, apresentamos o embasamento teórico do nosso trabalho e, no segundo, os resultados da pesquisa de campo, a saber, uma reflexão em torno das respostas apreendidas pela coleta de dados. E, por fim, apresentamos nossas considerações finais, nas quais discutimos sobre a importância deste trabalho para nossa formação enquanto pedagogas, tendo em vista que uma das nossas funções profissionais é assegurar o processo de ensino-aprendizagem de forma crítica e reflexiva.

Ednélia Francisco dos Santos e Eliane Rose Maio Braga 


\section{Embasamento Teórico: Discussões sobre Formação Docente, Gênero, Sexualidade, Educação e Brincadeira Infantil}

No decorrer desta pesquisa, observamos que, para analisar de que forma as brincadeiras infantis podem estruturar os papéis socialmente definidos na questão de gênero, seria preciso realizar um estudo anterior e mais amplo, que englobaria todos aqueles envolvidos neste processo.

Por essa razão, iniciamos nossas leituras a partir dos pressupostos teóricos que circunscrevem a formação docente, pois entendemos que o princípio de uma adequada educação, em especial no contexto atual em que a escola compete com outras instâncias educativas, às vezes muito mais rápidas e interessantes que a escola, como a televisão, a internet, etc., requer primeiramente, um/a professor/a bem formado/a.

Isto porque, na sociedade atual o/a professor/a precisa provar constantemente a sua função no processo de escolarização, já que as novas instâncias educativas tem tirado não apenas a importância destes/as, para as crianças e jovens, mas também tem se tornado muito mais ágil em trabalhar as informações (PIMENTA, 2002).

Para Vygotsky (2004) e Pimenta (2002) que viveram em épocas diferentes, a profissão docente não perdeu sua função com o processo da modernização, pelo contrário, ela continua sendo fundamental.

Pimenta (2002) afirma que o trabalho docente é fundamental na sociedade contemporânea, no sentido de mediar os processos constitutivos da cidadania dos alunos/as, para superação do fracasso e das desigualdades escolares. Vygotsky (2004) postula que a profissão docente no contexto moderno (também podendo ser aplicado ao contexto contemporâneo) é fundamental, pois, conforme esse autor, o meio social é determinante no processo educativo dos indivíduos, “(...) o meio social é a alavanca do processo educacional e todo o papel do mestre consiste em direcionar essa alavanca" (VYGOTSKY, 2004, p. 65).

Assim, analisando a sociedade atual, nos deparamos com um meio social contraditório e desigual: por um lado, o progresso evidencia as riquezas, frutos do processo de trabalho humano ao longo da história, que a condição humana pode desfrutar e, por outro, revela-se, também, uma sociedade desigual, na qual grande parte dos seres humanos está à margem dessas conquistas sociais (PIMENTA, 2002). Dessa forma, entendemos que a educação e, consequentemente, o/a professor/a deve ter a função de minimizar essa desigualdade por meio da prática educativa.
Para Carvalho (2010), esse contexto contraditório que vivemos hoje é fruto das transformações políticas, sociais e econômicas causadas pela crise do Capitalismo, isto é, esgotamento do modelo de acumulação Taylorista/Fordista, da administração Keynesiana e do Estado de bem-estar-social, da adoção do modelo Toyotismo e mundialização do capital.

Essa crise do Capitalismo provocou o aumento do desemprego, da exclusão social e forçou as economias centrais a 'não apenas reafirmar a importância da inclusão, mas também a elaborar políticas de reconhecimento e tolerância para com a diferença, visando, principalmente, a coesão social' (CARVALHO, 2010, p.8).

Dessa forma, a mudança no modelo da atividade econômica provoca também uma mudança nos contextos político, cultural e social, uma vez que, conforme Vygotsky (2004), na sociedade humana, os instintos de alimentação, de defesa, de multiplicação, redundaram na formação e no surgimento da atividade econômica e essa serve de base a todo desenvolvimento histórico da humanidade.

Na produção social da sua vida as pessoas entram em relações necessárias e independentes da sua vontade, relações de produção que correspondem a um determinado nível de desenvolvimento das suas forças produtivas materiais. $\mathrm{O}$ conjunto dessas relações de produção constitui a estrutura econômica da sociedade, base real em que se erige a superestrutura jurídica e política e a qual correspondem determinadas formas de consciência social (VYGOTSKY, 2004, p. 285).

Diante disso, entendemos que é sobre essa base que deve ser pensada a educação, em especial a educação escolar, uma vez que a educação, enquanto prática social, não se dá de forma isolada, mas dentro de um contexto político, econômico, cultural e histórico. No entanto, esse não é um trabalho simples, pois exige que tanto os indivíduos, como suas práticas sejam consideradas concretas, isto é, requer que o/a aluno/a, o/a professor/a e o meio educativo sejam pensados levando em consideração as práticas sociais e históricas que permeiam suas ações e comportamentos.

Por essa razão, uma das primeiras questões da educação e, consequentemente, dos cursos de formação de professores/as na atualidade é a análise da realidade social na qual ocorre o processo educativo, a saber, o (re) conhecimento da realidade histórica na qual se desenvolve a educação dos homens de hoje.

Ednélia Francisco dos Santos e Eliane Rose Maio Braga 
Em resumo, a educação escolar e os cursos de formação de professores/as não podem mais ignorar em sua prática diária as questões de gênero e sexualidade, pois essas temáticas também fazem parte da realidade social dos/as alunos/as. Pensando nisso, discutimos, a seguir, as temáticas de gênero, sexualidade e educação, a nosso ver, tão necessárias nas escolas atuais.

O âmbito escolar é cenário de muitas discussões a respeito dos mais variados assuntos, mas pouco se tem discutido sobre a questão de gênero e sexualidade. Uma das razões para isso é que nas escolas ainda impera um entendimento de gênero como sinônimo de sexo e de sexualidade ligada apenas à atração sexual. No entanto, como nos mostra Auad (2006, p.22), sexo não é a mesma coisa que gênero, apesar de estarem relacionados. $\mathrm{O}$ “(...) sexo é percebido como uma questão biológica, enquanto gênero é uma construção histórica a partir dos fatos genéticos".

Como afirma Braga (2009), o gênero vai sendo aprendido mesmo antes do nascimento, pois a partir do momento que sabemos o sexo da criança, criamos uma série de expectativas em torno do comportamento, da personalidade de meninos e meninas, e lançamos mão de práticas que reforçam e garantem essas expectativas. Por isso, quando presenteamos uma criança do sexo masculino com roupas azuis, brinquedos como carrinhos, armas de brinquedos, soldados etc., estamos tentando garantir que aquela criança construa características, habilidades esperadas para o seu gênero, a saber, virilidade, liderança, agressividade, que tenha controle sobre suas emoções, enfim, características culturais masculinas.

Em relação à menina, a prática é a mesma, as presenteamos com roupas cor de rosa, brinquedos 'sensíveis', como bonecas e utensílios de casa, porque, socialmente, espera-se que a menina chegue ao casamento e continue a reprodução da espécie. Embora saibamos que, na atualidade, os espaços sociais públicos e privados estão sendo ocupados tanto por homens quanto por mulheres, ainda permanece uma ideia equivocada de que as meninas devem ocupar os espaços privados e os meninos os espaços públicos. Por isso, ainda utilizam uma educação (informal) diferenciada para as meninas, com o objetivo de prepará-las para o matrimônio, priorizam-se práticas educativas - brincadeiras - que desenvolvam características tidas necessárias para esses papéis, como sensibilidade, obediência, emotividade, etc. Enquanto que para os meninos, cujo papel social esperado é o de provedor da família, o porto seguro da esposa e dos filhos, priorizam-se práticas educativas que desenvolvam as características tidas como masculinas, como liderança, força, objetividade, agressividade, não emotividade, entre outras.

No entanto, não há uma relação direta, biunívoca entre sexo e gênero, isto é, o sujeito do sexo masculino não necessariamente pertencerá ao gênero masculino, terá aquelas características culturalmente tidas como masculinas, da mesma forma o sujeito do sexo feminino. Isso ocorre porque a identidade de gênero não se resume a comportamentos (algo exterior), mas refere-se à maneira como o alguém se sente, se apresenta para si e para as demais pessoas, como homem ou mulher, isto é, refere-se a como o sujeito se identifica como masculino ou feminino (FIGUEIRÓ, 2008 apud BRAGA, 2010).

Para Auad (2006), gênero é um conjunto de ideias e representações sobre o masculino e o feminino que cria uma determinada percepção sobre o sexo anatômico. Ao se considerar as relações de gênero como socialmente construídas, percebemos que uma série de características consideradas 'naturalmente' femininas ou masculinas corresponde às relações de poder que atravessam esses gêneros. Assim, pensar a mulher como um ser frágil, meigo, delicado, emotivo, submisso, sentimental etc. não é um processo natural, mas histórico, fomos educados/as para isso. Da mesma forma, quando se refere ao homem, as características geralmente ligadas a este gênero como um ser viril, 'durão', com espírito de liderança, etc., também são socialmente construídas ao longo da história. Parafraseando Auad (2006), conforme o sexo anatômico que a criança tem, isto é, se tem pênis ou vulva, se é menino ou menina, homem ou mulher, é que se determinam quais serão as informações utilizadas para organizar esses sujeitos em uma desigual (e irreal!) escala de valores (AUAD, 2006).

Nesse sentido, a expressão gênero surge com o objetivo de marcar que as diferenças entre homens e mulheres não são apenas de ordem física e biológica, mas implicitamente de ordem social e histórica (BRAGA, 2010).

Louro (1997) afirma que a relação de gênero ganhou relevância nos discursos acadêmicos, primeiramente com o movimento feminista do século XIX, que tinha como concepção predominante, em relação às desigualdades sociais entre homens e mulheres, a distinção biológica para justificar as desigualdades sociais existentes. De acordo com essa concepção, “(...) homens e mulheres são biologicamente distintos e a relação entre ambos decorre dessa distinção, que é complementar e na qual cada um deve desempenhar um papel determinado secularmente (...)" (LOURO, 1997, p. 20). Embora tenha se passado mais de um século, essa ideia ainda permanece nos dias atuais

Mas já havia concepções no século XIX que

Ednélia Francisco dos Santos e Eliane Rose Maio Braga 
rebatiam a ideia que justificava as desigualdades de gênero a partir das diferenças de sexo. Hoje elas permanecem e postulam que:

(...) não são, propriamente, as características sexuais, mas a forma como essas características são representadas ou valorizadas, aquilo que se diz ou se pensa sobre elas que vai construir, efetivamente, o que é feminino ou masculino em uma dada sociedade e um dado momento histórico. Para que se compreenda o lugar e as relações de homens e mulheres numa sociedade importa observar não exatamente seus sexos, mas tudo o que socialmente se construiu sobre os sexos (LOURO, 1997, p. 21).

$\mathrm{O}$ fato de se dirigir o foco para o caráter fundamentalmente social do gênero não significa negar seu caráter biológico, mas enfatizar a construção social e histórica produzida a partir das características biológicas de homem e de mulher. Afinal, é no âmbito social que se constroem e se reproduzem as relações (desiguais) entre os sujeitos femininos e masculinos, e, portanto, são nas relações sociais que se devem buscar as justificativas para as desigualdades e não nas diferenças biológicas (LOURO, 1997). Por isso, pensamos que aqui reside a urgência em se trabalhar essas questões no contexto escolar.

$\mathrm{Na}$ medida em que o conceito afirma o caráter social do feminino e do masculino, obriga aquelas/es que o empregam a levar em consideração as distintas sociedades e os distintos momentos históricos de que estão tratando. Afasta-se (ou se tem a intenção de afastar) proposições essencialistas sobre os gêneros; a ótica está dirigida para um processo, para uma construção, e não para algo dirigido a priori (LOURO, 1997, p. 23).

No entanto, conforme Louro (1997), as características sociais e relacionais de gênero não devem levar a pensá-lo como se referindo à construção de papéis femininos e masculinos, mas como constituinte da identidade dos sujeitos. Os papéis sociais de homem e mulher são, essencialmente, padrões ou regras arbitrárias que uma sociedade coloca para seus membros, definindo seus comportamentos, suas roupas, seus modos de se relacionar ou de se portar, etc. "Através do aprendizado de papéis, cada um/a deveria conhecer o que é adequado (e inadequado) para um homem ou para uma mulher numa determinada sociedade e responder a essas expectativas" (LOURO, 1997, p. 24).

Quando homens e mulheres não correspondem a essas expectativas, ou seja, quando não se portam da forma tida como adequada a seu sexo pode ser taxado como homossexual (gay e lésbica). No entanto, as pessoas esquecem que identidade de gênero e identidade sexual são conceitos distintos, embora estejam relacionados. Identidade sexual refere-se a um jeito de ser, de se sentir, de vivenciar o seu afeto, refere-se a uma atitude política, ou a compartilhar uma cultura, uma música, lugares de encontro (BRAGA, 2010). Identidade de gênero, por sua vez, é entendida como:

uma experiência interna e individual do gênero de cada pessoa, que pode ou não corresponder ao sexo atribuído no nascimento, (...) é a percepção que uma pessoa tem de si como sendo do gênero masculino, feminino ou de alguma combinação dos dois, independente de sexo biológico. Trata-se da convicção íntima de uma pessoa de ser do gênero masculino (homem) ou do gênero feminino (mulher) (MARTINS; ROMÃO; LINDNER; REIS, 2012, p. 16).

Nesse sentido, discutir a questão de gênero, geralmente, implica discutir sexualidade. Ambos são conceitos distintos, mas estão inter-relacionados, assim como o gênero, a sexualidade também não é natural aos seres humanos, mas é construída nas relações sociais, culturais e históricas. Conforme Louro (2010, p. 11 - 12, grifos do original), a sexualidade "é uma invenção social, uma vez que se constitui, historicamente, a partir de múltiplos discursos sobre sexo: discursos que regulam, que normatizam, que instauram saberes, que produzem 'verdades"'.

Dessa forma, Louro (2010) entende que a sexualidade engloba rituais, linguagens, fantasias, representações, símbolos, enfim, processos culturais e plurais que definimos ao longo da história.

(...) o que é - ou não - natural; produzimos e transformamos a natureza e a biologia e, consequentemente, as tornamos históricas. Os corpos ganham sentido socialmente. A inscrição dos gêneros - feminino ou masculino - nos corpos é feita sempre no contexto de uma determinada cultura e, portanto, com as marcas dessa cultura. As possibilidades da sexualidade - das formas

Ednélia Francisco dos Santos e Eliane Rose Maio Braga 
de expressar os desejos e prazeres - também são sempre socialmente estabelecidas e codificadas. As identidades de gênero e sexuais são, portanto, compostas e definidas por relações sociais, elas são moldadas pelas redes de poder de uma sociedade (LOURO, 2010, p. 11).

Louro (2010) afirma que nossos corpos constituem a referência e deles surgem identidades. Assim, por meio das mais diversas imposições culturais, construímos nossos corpos de modo a adequá-los aos critérios estéticos, higiênicos, morais dos grupos aos quais pertencemos. Nesses processos de reconhecimento de identidades inscreve-se, ao mesmo tempo, a atribuição de diferenças.

O reconhecimento do 'outro' daquele ou daquela que não partilha dos atributos que possuímos é feito a partir do lugar social que ocupamos. De uma forma mais ampla, as sociedades realizam esses processos e, então, constroem os contornos demarcadores das fronteiras entre aqueles que representam a norma (que estão em consonância com seus padrões culturais) e aqueles que ficam fora dela, às suas margens (LOURO, 2010, p. 15, grifo do original).

A norma que se estabelece historicamente em nossa sociedade remete-se ao homem branco, heterossexual, de classe média, urbano, cristão e essa passa a ser a referência que não precisa mais ser nomeada, mas que servirá de modelo para a definição e diferenciação dos outros sujeitos sociais. Essa prática da sociedade, de classificação dos sujeitos, implica estabelecer divisões e atribuir rótulos para fixar as identidades. Portanto, ela tem o poder de definir, separar e também de distinguir e discriminar os sujeitos (LOURO, 2010).

Considerando esses aspectos, entendemos que a educação tem um papel importante na construção das identidades sociais, em especial, as de gênero e de sexo. Essas identidades, ao mesmo tempo em que podem definir e distinguir os sujeitos, elas podem também discriminá-los. Assim, as temáticas de gênero e de sexualidade devem estar presentes na escola desde o nível inicial até o nível superior, pois essa é uma boa chance de combatermos a discriminação e as desigualdades de gênero e de sexo nas nossas práticas diárias.

Quanto à Educação Infantil, Felipe (2008) afirma que um dos pontos fundamentais em relação ao trabalho com essas temáticas trata de “(...) problematizar e desconstruir o sexismo, a heteronormatividade e outros tipos de preconceitos" (FELIPE, 2008, p. 6), já que, geralmente, esses problemas são iniciados em casa, na maioria das vezes, por ignorância dos familiares em relação ao gênero e à sexualidade, podem ser reforçados, muitas vezes, dentro das escolas, onde deveria ser um lugar de acolhimento e de conhecimento de qualquer questão que atinja direta e indiretamente a vida dos/as alunos/as (FELIPE, 2008).

Dessa forma, Felipe (2008) afirma que os brinquedos e as brincadeiras são importantes instrumentos para se problematizar e desconstruir o sexismo, a heteronormatividade, pois, o brincar, nessa fase da vida, é o meio pelo qual a criança vivencia e apreende o mundo humano e tudo o que se relaciona com esse mundo, inclusive os papéis e funções sociais de homem e mulher. Ao brincar de faz de conta que é o pai, a mãe, o/a professor/a, o/a policial, etc., a criança internaliza conhecimentos em relação a esses papéis e funções sociais.

Por essa razão, a brincadeira apresenta uma função primordial na Educação Infantil, em especial no que se refere à construção da identidade de gênero. É justamente a respeito desse tema que seguimos com este texto.

A Educação Infantil é uma etapa da educação básica de suma importância para a formação do sujeito. Conforme a Lei de Diretrizes e Bases da Educação Nacional (LDB 9394/1996), esta etapa da educação tem como objetivos

I - proporcionar condições para desenvolvimento, físico, psicológico e intelectual da criança, em complementação a ação da família; II - promover a ampliação de suas experiências conhecimentos, estimulando seu interesse pelo processo de transformação da natureza e pela convivência em sociedade (BRASIL, 1990, p. 30).

Nesta etapa da vida da criança, a brincadeira desempenha um papel fundamental porque se constitui como um instrumento educativo que possibilita a apropriação do mundo, dos objetos humanos, da cultura humana (ROSSLER, 2006).

$\mathrm{Na}$ Educação Infantil, a criança tem como atividade principal a brincadeira, isto é, a atividade responsável por governar as mudanças mais importantes nos processos psíquicos e nos traços psicológicos da personalidade infantil (LEONTIEV, 1988). Conforme Leontiev (1988), a atividade principal caracteriza-se por três atributos: o primeiro é que se trata de uma atividade em que na forma surgem

Ednélia Francisco dos Santos e Eliane Rose Maio Braga 
outros tipos de atividade e dentro da qual eles são diferenciados, o segundo é que a atividade principal é aquela na qual processos psíquicos particulares tomam forma ou são reorganizados e o terceiro consiste em que:

(...) a atividade principal é a atividade da qual dependem, de forma íntima, as principais mudanças psicológicas na personalidade infantil, observadas em um certo período de desenvolvimento. É precisamente no brinquedo que a criança, no período pré-escolar, por exemplo, assimila as funções sociais das pessoas e os padrões apropriados de comportamento (LEONTIEV, 1988, p. 64 - 65).

Portanto, essa é uma forma de o gênero operar nas brincadeiras infantis estruturando o social e tornando os papéis, funções e processos de mulher e de homem possíveis e necessários. O comportamento de homem ou de mulher não é hereditário, mas adquirido por meio da experiência pessoal. Conforme Oliveira (2002), nas brincadeiras, a criança:

(...) vai gradativamente aprender a supor o que os outros pensam, buscando coordenar ativamente seu comportamento com o de seus parceiros. Para que consiga isso, irá brincar de ser muitas gentes: de ser mãe, pai ou bebê, depois de ser motorista (...) (OLIVEIRA, 2002, p. 52 - 53).

Para Vygotsky (2004), as particularidades históricas, geográficas, sexuais, individuais e de classe engendram e cultivam formas básicas do comportamento humano. A pessoa apresenta dois tipos de comportamentos, os comportamentos hereditários ou natos e os adquiridos. Os comportamentos hereditários são dados à criança logo quando nasce, ou também podem surgir no processo de seu crescimento, sem qualquer aprendizagem e influência de estranho e que, em linhas gerais, permanecem imutáveis ao longo de toda a sua vida.

Já as reações ou formas de comportamento adquiridas são aquelas que "surgem no processo de experiência pessoal no tempo mais variado e devem sua origem não a organização hereditária, mas as peculiaridades individuais da experiência pessoal" (VYGOTSKY, 2004, p. 20). Essa herança social é adquirida pelos homens por meio das mais variadas práticas sociais e históricas, dentre elas a brincadeira. "As primeiras ações lúdicas surgem com base na necessidade crescente da criança de dominar o mundo dos objetos humanos" (LEONTIEV, 1988, p. 135).

$\mathrm{Na}$ brincadeira infantil, as operações e ações das crianças são sempre reais e sociais e nelas as crianças adquirirem as formas de comportamento humano, se adaptam ao meio, apropriando-se da história da pessoa, isto é, da experiência histórica dos seres humanos. Para Vygotsky (2004, p. 25), "a brincadeira é uma forma natural de trabalho da própria criança, uma forma de atividade e também uma preparação para a vida futura", e essa preparação se dá em todos os sentidos, desde as mais simples reações e comportamento até às funções sociais de homem e de mulher, ou seja, a questão de gênero. Por exemplo, ao brincar de faz de conta desempenhando papéis de pai, mãe, professora, etc., a criança aprende as funções sociais e as regras de comportamento implícitas nesses modelos de adultos.

Nesse sentido, a brincadeira desempenha um importante papel na construção da identidade de gênero das crianças, e consequentemente, pode se constituir em um importante instrumento educativo no sentido de desconstruir os estereótipos de gêneros. No entanto, para que isso ocorra o/a professor/a deve:

(...) transmitir por meio de ações e encaminhamentos, valores de igualdade e respeito entre pessoas de sexos diferentes e permitir que a criança brinque com as possibilidades relacionadas tanto com o papel de homem quanto de mulher (BRASIL, 1998, p. 42).

Mas esse não é um trabalho simples, pois os estereótipos de gênero estão enraizados em nossa cultura. Comumente ouvimos frases como “(...) à mulher cabe cuidar da casa e dos filhos e ao homem cabe o sustento da família e a tomada de decisões, ou que homem não chora e que mulher não briga, entre outros" (BRASIL, 1998, p. 42). E então, o/a professor/a terá de desconstruir essa cultura, e, para isso, antes de tudo, precisará conhecer as discussões acerca das questões de gênero, pois, caso contrário, ele/a apenas reproduzirá os estereótipos de homem e mulher e contribuirá para as desigualdades de gênero.

Diante do exposto, no tópico seguinte, apresentamos os resultados da nossa pesquisa de campo no Centro de Educação Infantil Casa de Davi, em São Tomé, situado no terceiro planalto paranaense e pertencente à Microrregião de Cianorte (cidade do noroeste do estado). Encontra-se aproximadamente a 530 quilômetros de Curitiba. Sua população é de aproximadamente 5.349 habitantes e a economia é baseada na agricultura, na pecuária e nas indústrias de pequeno porte.

Ednélia Francisco dos Santos e Eliane Rose Maio Braga 


\section{Pesquisa de Campo: Experiências e Resultados}

Com o objetivo de apreender o conceito que as professoras e a equipe pedagógica do Centro de Educação Infantil Casa de Davi têm sobre a questão do gênero nas brincadeiras infantis, adotamos, neste trabalho, a pesquisa qualitativa e, para a coleta de dados, a técnica da entrevista semiestruturada.

Para tanto, elaboramos um questionário com nove (9) perguntas, e o aplicamos a onze (11) professoras e uma (1) pedagoga da referida instituição de ensino. Estas foram as questões: 1) Qual a sua idade? 2) Qual seu curso de formação? 3) Qual turma (berçários I e II, maternais I, II, III e pré I e II) você trabalha? 4) Para você, o que é gênero? 5) Para você, o que é brincadeira? 6) Como você encaminha as brincadeiras dos (as) seus (suas) alunos (as)? 7) Qual o critério de seleção para a compra dos brinquedos da instituição em questão? 8) Qual a preferência dos/as alunos/as em relação às brincadeiras tidas como de menino e de menina? 9) Como você agiria se na brincadeira de faz de conta o menino quisesse ser a mãe ou a menina ser o pai? Essas questões foram respondidas por escrito pelas professoras, na própria instituição, durante $o$ intervalo das aulas. Para realizar tal procedimento, este projeto foi submetido e aprovado pelo Comitê de Ética de Pesquisa com Seres Humanos da UEM, com o $\mathrm{n}^{\circ}$ 255/2010.

A análise de dados se deu a partir de um longo processo de leitura e releitura que culminou na construção de categorias de análise, tendo como critério as semelhanças entre as respostas das professoras. Essa categorização ocorreu apenas a partir da quarta questão, já que as três primeiras diziam respeito à identificação dos sujeitos de pesquisa.

Dessa maneira, com relação à quarta questão, a saber, o entendimento sobre o que é gênero, as respostas foram classificadas em três grupos: o primeiro grupo engloba aquelas professoras que tiveram dificuldade para responder à questão e, por isso, recorreram ao dicionário, descaracterizando, assim, suas respostas, já que não expressaram suas ideias de gênero. Destacamos uma das respostas:

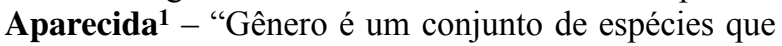
distingue palavras em masculinas, femininas ou neutras".

O segundo grupo de respostas refere-se ao das professoras que compreendem gênero como se fosse sinônimo de sexo, isto é, como se houvesse uma correspondência natural entre sexo e gênero, nesses casos, sexo masculino - gênero masculino, sexo feminino - gênero feminino. Como por exemplo, a resposta da professora Ana: "Gênero se refere ao sexo da criança se masculino ou feminino".

O terceiro grupo de respostas compreende aquelas professoras que se aproximaram mais da concepção de gênero entendida e defendida por nós, nesse trabalho, isto é, o gênero não como sinônimo de sexo ou como um processo natural garantido no momento do nascimento, mas como uma construção social e histórica que vai sendo construída pelo conjunto das pessoas ao longo da história. Francisca é uma das professoras que em sua resposta parece compreender que o gênero não é sinônimo de sexo, segundo ela: "Gênero é se sentir feminino ou masculino".

Em relação à quinta questão, isto é, da compreensão das professoras sobre a brincadeira na Educação Infantil, classificamos, novamente, as respostas em três grupos: o primeiro refere-se às professoras que associam a brincadeira ao prazer, à imaginação, no sentido de uma atividade fantástica, como responde Aparecida: "Brincadeira é recreação, ação de brincar e divertir".

Para Leontiev (1988) e Vygotsky (1989), o prazer está associado à brincadeira, mas ele não pode ser sua característica definidora, porque nem todas as brincadeiras são prazerosas para as crianças, os jogos com regras fixas, por exemplo, serão prazerosos apenas para a criança que atingir o objetivo da brincadeira. Assim, afirmam esses autores, a brincadeira na idade pré-escolar tem como característica definidora a necessidade da criança de agir sobre o mundo dos objetos humanos, principalmente aqueles que pertencem ao mundo do adulto. A criança não brinca por causa do prazer que a brincadeira proporciona, mas porque ela lhe permite agir como um adulto com os objetos dos adultos, ainda que em um contexto imaginário, simbólico.

O segundo grupo de respostas associa a brincadeira a um resultado objetivo, como podemos observar na resposta de Carla: "Brincadeira é uma das formas de se trabalhar com as crianças, as brincadeiras tanto podem ser direcionadas como também livres".

Mas, conforme Leontiev (1988), o uso da brincadeira visando a um resultado objetivo específico, descaracteriza esta atividade, porque o objetivo da brincadeira não está no resultado, mas sim no próprio processo de brincar. A criança brinca não porque a brincadeira a tornará mais inteligente, mais ágil, mais social, ela brinca pelo processo da brincadeira, isto é, o processo lúdico, no qual ela age não como uma criança, mas como adulto - esse é o motivo da brincadeira.

O terceiro grupo de respostas é aquele que as professoras reconhecem o papel dominante da brincadeira na idade pré-escolar, mesmo que de forma subjetiva, são respostas como da professora

Ednélia Francisco dos Santos e Eliane Rose Maio Braga 
Francisca: "Brincadeiras são as atividades em que a criança se diverte, se envolve, solta a imaginação, aprende conceitos, regras, faz amizade, socializa com os demais amigos. Pelo faz de conta com a troca de papéis eles se transformam em outros personagens e revive questões do seu cotidiano, familiares, perdas, ressentimentos, etc. Por meio do lúdico, ele aprende infinitas coisas que poderia não compreender de outras formas".

Embora esta compreensão da brincadeira ainda seja de uma minoria das professoras, consideramos isso um avanço para a Educação Infantil, pois analisando sua história recente percebemos que a brincadeira era tida como um passatempo para as crianças, um momento para elas relaxarem.

A sexta questão compreende a forma com que elas encaminhavam as brincadeiras na sua prática diária de sala de aula. Em relação a essa questão, suas respostas giraram em torno de três critérios: faixa etária das crianças; tipo livre ou direcionado; e objetivo da brincadeira. Como por exemplo, a resposta da professora Vera: "Procuro encaminhar brincadeiras que são de acordo com a idade dos meus alunos, sendo essas aplicadas com objetivos, de forma lúdica a fim de estimulá-los a realizar as mesmas quando são direcionadas. Quando as atividades são livres procuro observá-los para analisar se as crianças estão se socializando, sendo criativas, participativas e até mesmo se estão usando a imaginação".

Basicamente, em todas as respostas, as professoras evidenciaram que o encaminhamento das brincadeiras era feito sempre de acordo com algum objetivo, seja a coordenação motora, a socialização, etc., ou seja, algo fora da brincadeira. No entanto, conforme vimos anteriormente com Vygotsky (1989) e Leontiev (1988), a brincadeira não precisa de um objetivo fora da brincadeira, pois, o motivo da brincadeira é o próprio processo lúdico. Para Leontiev (1988), a característica principal da brincadeira é que seu alvo reside no próprio processo e não no resultado da ação. Assim, "a ação lúdica é psicologicamente independente de seu resultado objetivo, porque sua motivação não reside nesse resultado" (LEONTIEV, 1988, p. 126).

A sétima questão diz respeito aos critérios de seleção para compra dos brinquedos da instituição. As respostas das professoras evidenciaram que há bastante tempo a instituição não faz compra de brinquedos, mas quando isso ocorre, ela dá prioridade aos brinquedos pedagógicos e alguns não pedagógicos. Disseram que a aquisição de brinquedos para a instituição tem ocorrido por meio de doações das famílias dos/as alunos/as, da comunidade ou, também, são confeccionados pelas professoras, juntamente com os/as alunos/as com sucatas (materiais recicláveis).
A oitava questão refere-se à preferência dos/as alunos/as em relação às brincadeiras tidas como de menino ou menina. Em relação a essa questão, as respostas das professoras evidenciam que a diferenciação das brincadeiras pelo gênero masculino e feminino aparece mais claramente nas turmas de pré I e II, nas quais as crianças são maiores, estão entre quatro a cinco anos. Já nas turmas do berçário e do maternal, que as crianças são menores, essa questão quase não apareceu, foi relatado que elas brincam de tudo sem questionar. Para ilustrar essas afirmações, apresentamos as respostas de Izabel, professora do pré II, e de Silvia, professora do maternal II. Silvia: "Minha turma é o maternal II (3 a 4 anos) eles brincam de tudo e juntos. Exemplo: bolas, bonecas, carrinhos, etc." Izabel: "Dentro da minha sala percebo que as crianças brincam de acordo com seu sexo. Até quando brincam de casinha as meninas são mamães e os meninos são os papais. Meninas são sempre meninas e meninos são sempre meninos".

Essa constatação mostra que a diferenciação social dos gêneros masculino e feminino é aprendida pela criança na medida em que elas são interpeladas pelas mais variadas práticas sociais, entre as quais está a brincadeira, o vestuário, etc. Quando esse aprendizado ainda não ocorreu, como é o caso das crianças menores, as crianças brincam sem se importarem com os estereótipos de gênero, elas escolhem a brincadeira de acordo com sua vontade.

Outro aspecto em relação aos estereótipos de gênero é que os meninos têm mais resistência em brincar com as brincadeiras e brinquedos estereotipados como de meninas, como evidencia a resposta da professora Vera, também do pré II. Para ela, durante a brincadeira, "os meninos pegam os carrinhos, as peças de montar e os animaizinhos da fazenda e nada que é taxado pela sociedade como sendo de menina, como por exemplo, boneca e objetos cor de rosa. Já as meninas brincam de casinha com as bonecas e as panelinhas, mas, às vezes se juntam para brincar com os meninos de fazendinha e, mesmo assim, eles não querem saber das bonecas nem dos objetos cor de rosa".

A nona questão indagava como elas agiriam se na brincadeira de faz de conta o menino quisesse ser a mãe ou a menina ser o pai. Em relação a essa questão, percebemos que as professoras responderam aquilo que acreditavam e algumas até argumentavam com as outras tentando defender seu ponto de vista, assim houve um pequeno debate entre duas professoras, a Aparecida e a Silvia, que tinham visões diferentes sobre a função social dos gêneros. Aparentemente, uma delas era bastante tradicional, conservadora em relação à função social de homem e de mulher, isto é,

Ednélia Francisco dos Santos e Eliane Rose Maio Braga 
carregava uma visão pautada nos estereótipos. A outra professora parecia ter uma concepção diferente sobre a função social dos gêneros masculino e feminino, uma concepção que defendemos nesse trabalho, isto é, que entende que o gênero não se restringe aos papéis sociais de homem e de mulher, mas engloba "todas as formas de construção social, cultural e linguística implicadas com os processos que diferenciam mulheres de homens (...)" (MEYER, 2003, p. 16).

A fim de refletir sobre essas concepções, destacamos, a seguir, as respostas das professoras. Aparecida: "Explicaria para eles (as) que, normalmente e, na realidade, a menina é a mãe e o menino é o pai" - durante a entrevista essa professora argumentava com outras professoras que não deixaria seus (as) alunos (as) brincarem assim, ainda mais na sociedade de hoje. E justificava sua resposta recorrendo a questão dos pais, o que ela falaria para os pais se eles chegassem e vissem os (as) seus (as) filhos (as) brincando que é a mãe ou o pai da boneca e eu, como professora sendo conivente com essa situação. Rosa: "Eu agiria com a maior naturalidade se o menino quisesse ser a mãe e a menina ser o pai na brincadeira de faz de conta, pois isso são cenas vivenciadas no seu dia a dia. Eu, enquanto professora, não interferiria no momento e iria a partir deste daí, observar com mais ênfase seu comportamento".

As demais professoras se contradisseram em suas respostas, pois responderam que não interfeririam e deixariam as crianças brincarem, mas explicariam antes que o papai é o menino e a mamãe é menina. Como por exemplo, Silvia: "Eu explicaria que papai seria o menino e mamãe a menina e por fim deixaria eles à vontade, pois ainda são muitos pequenos, têm de dois a três anos e não têm formação formada".

Embora o gênero não se restrinja aos papéis sociais de homem e de mulher, percebemos que esse é o entendimento que a maioria das pessoas tem (inclusive as professoras), conforme mostramos. A nosso ver, isso é preocupante, já que esse tipo de pensamento tem sido um problema para a materialização da educação com base na igualdade de gênero, difundida pelos discursos atuais sobre a educação de gênero.

Essa concepção está presente no/a professor/a que teoricamente é o sujeito mais culto, esclarecido, entre as demais pessoas que compõem o núcleo principal do processo de ensino-aprendizagem (pais/mães, alunos/as e professores/as). Quando, na verdade, o/a professor/a deveria esclarecer aos demais componentes desse grupo sobre os conhecimentos que afetam direta ou indiretamente suas vidas - o gênero e a sexualidade -, já que quando se trata desses conhecimentos os/as pais/mães são um dos complicativos para a efetivação desse trabalho. Principalmente, quando se trata da
Educação Infantil, pois as professoras têm muitas dúvidas em como lidar com algumas situações que surgem no cotidiano da escola, como a desaprovação dos/as pais/mães em relação ao comportamento do/a seu/sua filho/a. É o caso do exemplo citado pela professora Lurdes:

Houve um caso, o ano passado (2009), que a mãe nos exigiu que não deixássemos o filho dela brincar de boneca, usar cores rosa, enfim 'tudo que é de menina', porque na casa deles ele só queria as coisas de menina. Por isso queria que a escola tirasse essa ideia da cabeça dele.

De fato, os/as professores/as não sabem como lidar com essas situações porque não têm conhecimento científico acerca da sexualidade e do gênero. Esse tipo de conhecimento ainda não faz parte dos conhecimentos adquiridos nas universidades, nem faz parte dos cursos de formação continuada.

Assim, diante do exposto, concluímos que uma das principais questões quando se refere ao trabalho com as temáticas de gênero e de sexualidade nas escolas, ou melhor, quanto se refere ao não trabalho com estas temáticas no contexto escolar, o problema está sempre na formação dos/as professores/as, são eles/as os/as responsáveis por materializar a educação no 'chão' da escola. É o/a professor/a que por meio da sua prática pedagógica possibilitará aos/às alunos/as a reflexão sobre os conhecimentos a serem aprendidos, sejam eles, álgebra, gramática, gênero ou sexualidade. Dessa forma, se o/a professor/a não domina os conhecimentos sobre gênero e sexualidade, certamente, não poderá problematizá-los e provocar a reflexão de seus/suas alunos/as e, portanto, os ensinará (se ensinar) como uma verdade absoluta. Mas bem sabemos que conhecimento nenhum é verdade absoluta, pois os conhecimentos são históricos e, por isso, suscetíveis a mudanças. Por exemplo, os conhecimentos sobre gênero e sexualidade, se um dia pensou-se em gênero como sinônimo de sexo, hoje, conforme mostramos neste trabalho, gênero ganhou estatuto de construção social e histórica feita a partir dos fatos genéticos, a partir dos sexos masculino e feminino (AUAD, 2006). Da mesma forma, a sexualidade não se resume a corpos - supondo que estes são vividos, universalmente, da mesma forma, mas ela engloba rituais, linguagens, fantasias, representações, símbolos, enfim, processos culturais e plurais de se fazer homem e mulher.

Ednélia Francisco dos Santos e Eliane Rose Maio Braga 
1 Os nomes são fictícios para preservar a identidade das professoras.

\section{Referências}

AUAD, Daniela. Educar meninas e meninos: relações de gênero na escola. São Paulo: Contexto, 2006.

BRAGA, Eliane Rose Maio. Gênero, sexualidade e educação: questões pertinentes à pedagogia. In: CARVALHO, Elma Julia Gonçalves de; FAUSTINO, Rosangela Célia (Org.). Educação e diversidade cultural. Maringá - Paraná: Eduem, 2010, p. 205 - 218.

BRAGA, Eliane Rose Maio. Diversidade Sexual: discussões pedagógicas. In: SILVA, Henrique Manoel; CELÓRIO, José Aparecido; SILVA, Márcia Cristina do Amaral (Orgs.). Saberes e Sabores da Educação. Maringá - Paraná: Eduem, 2010, p. 49 - 58.

BRASIL. Ministério da Educação e do Desporto. Secretaria de Educação Fundamental. Referencial Curricular Nacional para a Educação Infantil: Formação Pessoal e Social. Brasília, DF: MEC/SEF, 1998, v.2.

CARVALHO, Elma Júlia Gonçalves de. Educação e Diversidade cultural. In: CARVALHO, Elma Júlia Gonçalves de; FAUSTINO, Rosangela Célia (Org.). Educação e diversidade cultural. Maringá, PR: Eduem, 2010, p. 17 - 54.

CHIZZOTTI, Antonio. A pesquisa qualitativa em ciências humanas e sociais: evolução e desafio. Revista Portuguesa de Educação, v. 16, n. 2, p. 221 236, 2003

FELIPE, Jane. Proposta Pedagógica. In: BRASIL. Ministério da Educação. Secretaria de Educação à distância. Salto para o futuro: educação para a igualdade de gênero. Rio de Janeiro: Ministério da Educação. Secretaria de Educação à distância, nov. 2008. ano 18 , v. 26 , p. 3 - 14.

LEONTIEV, Alexis N. Os Princípios Psicológicos da Brincadeira Pré-escolar. In: VYGOTSKY, Lev Semenovich.; LURIA, Alexander R.; LEONTIEV, Alexis N. Linguagem, Desenvolvimento e Aprendizagem. São Paulo. Universidade de São Paulo, 1988, p. 119 - 142.

LOURO, Guacira Lopes. Pedagogias da Sexualidade.
In: LOURO, Guacira Lopes. (Org.). O corpo educado: pedagogia da sexualidade. 3 ed. Belo Horizonte: Autentica, 2010, p. 7 - 34.

LOURO, Guacira Lopes. Gênero, sexualidade e educação: uma perspectiva pós-estruturalista. Petrópolis, RJ: Vozes, 1997.

LUDKE, Menga; ANDRÉ, Marli E. D. A pesquisa em educação: abordagens qualitativas. São Paulo: Editora Pedagógica Universitária, 1986.

MARTINS, Ferdinando; ROMÃO, Lilian; LINDNER, Liandro; REIS, Toni. Manual de Comunicação LGBT - Lésbicas, Gays, Bissexuais, Travestis e Transexuais. Disponível em: $<$ http://redalyc.uaemex.mx/pdf/374/37416210.pdf $>$. Acesso em: 03 abr. 2012.

MEYER, Dagmar Estermann. Gênero e Educação: teoria e política. In: LOURO, Guacira Lopes; VILADORE, Silvana (Org.). Corpo, gênero e sexualidade: um debate contemporâneo na educação. 2 ed. Petrópolis, RJ: Vozes, 2003, p. 9 - 27.

OLIVEIRA, Zilma Ramos. Educação Infantil Fundamentos e Métodos. São Paulo: Cortez, 2002.

PIMENTA, Selma Garrido. Formação de professores: identidade e saberes da docência. In: PIMENTA, Selma Garrido. (Org.). Saberes pedagógicos e atividade docente. 3 ed. São Paulo: Cortez, 2002, p. $15-34$.

ROSSLER, João Henrique. O papel da brincadeira de papeis sociais no desenvolvimento do psiquismo humano. In: ARCE, Alessandra; DUARTE, Newton (Orgs.). Brincadeira de Papeis Sociais na Educação Infantil: As contribuições de Vygotsky, Leontiev e Elconin. São Paulo: Xamã, 2006. p. 51 - 63.

VYGOTSKY, Lev Semenovich. A formação social da mente. 3 ed. São Paulo: Martins Fontes, 1989.

VYGOTSKY, Lev Semenovich. Psicologia pedagógica. 2 ed.: São Paulo: Martins Fontes, 2004.

Recebido em 18 de abril de 2012. Aceito em 25 de agosto de 2012. 